\title{
Dysmenorrhea in School Area in Benin
}

\author{
Tshabu Aguemon C*, Yunga F. J-D, Hounkponou F, Kpokoun E, Takpara I, Adisso S \\ Health science faculty of Abomey Calavi University, Benin
}

Received: December 29, 2015; Accepted: May 26, 2016; Published: May 30, 2016

*Corresponding author: Tshabu Aguemon Christiane, Health science faculty of Abomey Calavi University, BP 1878, Benin; E-mail: caguemon@yahoo.fr

\begin{abstract}
Introduction: Described since antiquity and long been considered as an Epiphenomenon Dysmenorrhea benefit since some years from a renewal of interest. The aim was to determine the prevalence and the social impact of Dysmenorrhea in school area.

Method and patients: It was a prospective, analytical and descriptive study, basing on a sample of 512 students in Cotonou during a period of 4 months (from March to June 2014).

Results: The global prevalence of Dysmenorrhea in school environment was high in $65.6 \%$. The majority of investigated students $(58.6 \%)$ is between 16 and 20 years old and is for the most part bachelors (96.6\%). The essential Dysmenorrhea represented 49.1\%. Premenstrual dysmenorrhea represented $51.5 \%$ followed by protomenial dysmenorrhea $36.5 \%$ then tele-menial dysmenorrhea $10.9 \%$. The family backgrounds of dysmenorrhea was found in $37.3 \%$ ( $\mathrm{p}=$ 0.001). The dysmenorrhea was responsible of school absenteeism in $32.1 \%$ of cases. The statistical analysis had made that, there is a relation between the age and the dysmenorrhea $(\mathrm{p}=0.021, \mathrm{OR}=1.83$ $[1.04 ; 3.20])$; the proportion of painful menses women is more important at the less than 20 years (67.4\%) than in the row of more than 20 years $(32.6 \%)$.
\end{abstract}

Conclusion: Dysmenorrhea in the teenager is becoming more and more frequent during gynecological consultation in our department. It affects more than one teenager over three during our survey.

Keywords: Female pupils; Dysmenorrhea; Psycho-social influence;

\section{Introduction}

Dysmenorrhea is a real public health problem. It was described since antiquity, and has been considered for a long time as an epiphenomenon. Dysmenorrhea knows since few years a regain of interest. Recent study indeed underlined the role of a uterine hyper contractibility associated with dysregulation of the synthesis of some uterine prostaglandins. It resulted a more coherent physio-pathological conception, and thereby, a better adapted therapeutic management $[1,2,3]$. According to Dawood, $50 \%$ of women complain of simple pain and $10 \%$ of the invalidating form. Nevertheless $79 \%$ of teenagers are attained by dysmenorrhea and $18 \%$ of them have the invalidating form according to Robinson [3, 4]. Dysmenorrhea had a considerable importance in socio-professional life of girls by conditioning their immobilization, their scholar absence, their sportive and intellectual counter performance, their sick stop. At this important socio-professional dimension, is added the psychosocial impact and their repercussion in the psychism [5].

The aims were to identify the different factors susceptible to influence Dysmenorrhea in school environment and to study the psycho-social impact on the quality of the pupil's life.

\section{Patients and Methods}

The study was proceeded in four secondary school in Benin. Two public and two private: general teaching public college "Nokoué", general teaching public college "Pylônes", private teaching college "Marthin Luther King" and private college "Vatican". It was about a transversal, descriptive and analytical study, over a 4 months (March to June2014).The female pupils regularly registered in these 4 schools, having already menses and having freely agreed were included in the study. The sample size was determined by the formula of $\operatorname{Schwartz}(\mathrm{x}=1.96, p=0.79$, $\mathrm{i}=5 \%$ ). In accordance with the formula of Gauss, we multiply manpower by $2(\mathrm{~N}=509.85)$. The size of our sample was rounded to 512 pupils. We proceeded by simple random sampling: the first pulling of six districts of Cotonou of the thirteen, then the second pulling of three districts out of six. Then we indexed the public and the private schools in the three selected districts. We chose two privates and two publics by lot. Thus according to the size of our sample, we chose 128 girls randomly per school. As soon as one entered the school yard during the recreation, the first 128 girls met according to our criteria were selected. A specimen of enlightened assent was presented after a short explanation before the handing-over of the questionnaire. To respect the confidentiality, a ballot box was laid out in the secretariat of each school to slip there the filled out cards which we recovered at the end of each week. The entry and the data analysis were done by SPSS 21 software. The proportions were used to describe the qualitative variables. The average, and the standard deviation in one side or the median and the interquartile interval in the other side, were used to describe the quantitative variables. As for the comparison of the proportions, when the conditions are present, we use the CHI2 test of Pearson, the corrected test of Chi test of Yates and test of Fischer. When there is a link between 2 variables we used Odds Ratio. We chose to work with a risk of error of $5 \%$. If the degree of significativity is $p<0.05$, there is a significant relation.

\section{Results}

We recorded 512 pupils; only $65.5 \%$ of them were suffering 
Table 1 : Division by type of triggering factors.

\begin{tabular}{|l|l|l|}
\hline Triggering factors & Effective & Percentage (\%) \\
\hline High Genital infection & 14 & 4.16 \\
\hline First Sex relation & 11 & 3.27 \\
\hline Spontaneous abortion & 4 & 1.19 \\
\hline Delivery & 2 & 0.59 \\
\hline Induced abortion & 1 & 0.3 \\
\hline Infection & 1 & 0.3 \\
\hline Spontaneous & 303 & 90.17 \\
\hline Total & 336 & 100.0 \\
\hline
\end{tabular}

of Dysmenorrhea. The age means was 17 years with extreme of 10 and 25 years. The dominant age range was 16 to 20 years (62.2\%). The majority of the student are single (96.6\%) and were Beninese. The pupils which had their first menses between 13 and 15 years represented 65.8\%. The age means of the beginning of menses was 13 to 17 years (Min=9 Max=19 standard deviation=1.7). The majority of the pupils had irregular cycle (61.1\%), primary dysmenorrhea $49.1 \%$ and secondary dysmenorrhea 50.9\%. In 4.16\%, dysmenorrhea started after an upper genital infection Table 1. Premenstrual dysmenorrhea represented $51.5 \%$ followed by proto-menial dysmenorrhea $36.5 \%$ then tele-menial dysmenorrhea $10.9 \%$. The average duration of the pains was 2.9 days ( $\min =1, \max =6$, standard deviation 1.4, median, 3.0). According to the scale of Sultan, the severe and moderated dysmenorrhea was found respectively in $40.1 \%$ and $44.1 \%$. More than half of the pupils are suffering from Dysmenorrhea (50.5\%) announced asthenia like signs accompaniment Table 2. More of the third of the dysmenorrhea pupils $45.8 \%$ announced that the pain menses increased with the years and $32.8 \%$ announced that the pain menses did not vary. The family antecedent of dysmenorrhea was found in $56.8 \%$. The majority of dysmenorrhea pupils $97.3 \%$, did not have a surgical antecedent. The statistical analysis had made that, there is a relation between the age and the dysmenorrhea $(p=0.021$, OR $=1.83[1.04 ; 3.20]$ ); the proportion of painful menses women is more important at the less than 20 years $(67.4 \%)$ than in the row of more than 20 years (32.6\%). A link is between dysmenorrhea and matrimonial situation $(p=0.002$ OR $=1.70$ [0.90; 3.23]) the single pupils $60.5 \%$ makes more dysmenorrhea than the others. There is no link between the dysmenorrhea and the age of the first menses ( $p=0.201)$. There is no link between the duration of the cycle and the painful menses $(p=0.026, \mathrm{OR}=1.52[1.03$; $2.25])$. There is no link between the use of contraceptive method and dysmenorrhea ( $p=0.085, \mathrm{OR}=1.7[0.93 ; 2.33])$. There is no link between the upper genital infections and the dysmenorrhea $(p=0.474, \mathrm{OR}=1.7[0.75 ; 1.84])$. There is a link between the family antecedent of dysmenorrhea (37.3\%) and coming up of painful menses to the pupil $(p=0.001, \mathrm{OR}=2.25[1.52 ; 3.33]$ Table 3. The school absence the first day of the menses was noted at $32.1 \%$; there is a link between the intensity of the pain and the absence in class $(p=0.001)$. The premenstrual moral state for the majority of dysmenorrheic appeared by nervousness (42.9\%) with the approach of menses, by unhappiness (33.9\%) and the

others are indifferent. The majority from painful menses patients $58.3 \%$ declared that the pain did not obstruct at all their social life; on the other hand for $8 \%$, dysmenorrhea had an enormous impact on their social life. $38.7 \%$ of painful menses pupils thought that the dysmenorrhea was normal and $44.0 \%$ thought that the pain was a momentary state Table 4.

\section{Discussion}

The frequency of dysmenorrhea is variable in the literature. Wildhom [6] in Norway, over 5000 female school pupils interrogated, $13 \%$ had constantly painful menses, and $38 \%$ had it occasionally either a global frequency of $51 \%$ of dysmenorrhea. According to Klein [7], the frequency of dysmenorrhea increases with age (39\% at the age of 12 years and $72 \%$ at the age of 17); it increases no matter the age when gynecological life passes 2 years. The age means in our survey was 14.37 years. The strongest rate of dysmenorrhea was found in the 15 years old patients. We observed a progressive increase of dysmenorrhea frequency as from the age of 16 years. The majority of the teenagers were nulligestes $(84.6 \%)$ and the nulliparous ones (93\%).The nervous mechanisms of the dysmenorrhea make it possible to explain this phenomenon. Indeed there is a regression even the disappearance of the menstrual pains after a pregnancy carried out in long in term. It makes think that the uterine innervation is completely altered and deteriorated by pregnancy [8]. It is not the simple fact of the state of pregnancy since dysmenorrhea does not disappear after a miscarriage or a voluntary interruption of pregnancy in the first term. This phenomenon is not constant since NG [9] finds $60 \%$ of dysmenorrhea after the first childbirth. We observed $7 \%$ of dysmenorrhea after the first childbirth. The pelvic surgery with effraction in uterine cavity exposes to uterine synechia responsible of secondary dysmenorrhea. In our survey, 2 painful menses patients had an antecedent of caesarian and one painful menses patient had the antecedent of myomectomy. Out of our survey, $60.8 \%$ had their first menses after the age of 13 years and $24.8 \%$ before the age of 13 years. Andersch [3] finds that dysmenorrhea is higher if the first menses occurs earlier. We found $53.2 \%$ of genital and urinary infection antecedent. Dysmenorrhea can occur in certain cases at the ending of a pelvic infection syndrome. Although coelioscopy does not always objectify visible adherences or lesions, the responsibility for the infectious process old sometimes, is to be retained [10]. The intensity of the pain appreciated at the scale

Table 2 : Division of dysmenorrhea by type of malaise.

\begin{tabular}{|l|l|l|}
\hline Type & Effective & Percentage (\%) \\
\hline Wickness & 107 & 50.5 \\
\hline Loss of appetite & 77 & 36.3 \\
\hline Bad feeling & 36 & 17.0 \\
\hline Hungry & 35 & 16.5 \\
\hline Head ache & 32 & 15.1 \\
\hline Vomissement & 31 & 14.6 \\
\hline Nausea & 24 & 11.8 \\
\hline Lots of knowledge & 5 & 02.3 \\
\hline
\end{tabular}

Citation: Tshabu AC, Yunga FJD, Hounkponou F, Kpokoun E, Takpara I, et al. (2016) Dysmenorrhea in School Area in Benin. SOJ 
Table 3 : Factors can influenced the dysmenorrhea.

\begin{tabular}{|c|c|c|c|c|c|}
\hline & Effective & Effective Percentage \% & Not Effective & Not Effective Percentage \% & \\
\hline IMC (18-25) & 294 & 57.4 & 143 & 27.9 & $\mathrm{P}=0.078$ \\
\hline Age (16-20 ans) & 209 & 40.8 & 91 & 17.7 & $\mathrm{P}=0.021$ \\
\hline Single & 310 & 60.5 & 154 & 30.0 & $P=0.002$ \\
\hline Menarche (13-15 ans) & 214 & 41.7 & 123 & 24.0 & $\mathrm{P}=0.201$ \\
\hline Cycle irregular & 219 & 42.7 & 97 & 18.9 & $\mathrm{P}=0.026$ \\
\hline Flow of menstruation more than two days & 260 & 50.7 & 124 & 24.2 & $P=0.144$ \\
\hline Use of familly planning & 244 & 47.6 & 140 & 27.3 & $\mathrm{P}=0.085$ \\
\hline More than two girl in the fratry & 271 & 52.9 & 143 & 27.9 & $\mathrm{P}=0.871$ \\
\hline No sexual disease transmission & 250 & 48.8 & 136 & 26.5 & $\mathrm{P}=0.474$ \\
\hline No chirurgical antecedent & 244 & 47.6 & 140 & 27.3 & $\mathrm{P}=0.085$ \\
\hline Good relationship with parents & 115 & 22.4 & 70 & 13.6 & $\mathrm{P}=0.646$ \\
\hline Antecedent familial of dysmenorrhea & 191 & 37.3 & 65 & 12.6 & $P=0.001$ \\
\hline
\end{tabular}

of Sultan (EVS) had shown $37.9 \%$ of moderated pain during the menses and $6.1 \%$ had a very intense pain. The other cases are of $33.6 \%$ for the weak pains and $22.4 \%$ for the intense pains. With the score of numeric scale $65.3 \%$ had a clinical score ranging between 4 and 7 (moderate pain) and $16.4 \%$ of the patients with a clinical score ranging between 8 and 10 (unbearable pain). We note that results got on simplified verbal scale (E.V.S) and on numeric scale are very different. There might be either an over estimation of the pain intensity either a difficulty in patients to understand the principle of evaluating the pains that they felt. The socio-economic repercussion of the dysmenorrhea was evaluated by the absentee rate. In our series we found $37.4 \%$ of absenteeism. CH. Sultan [11] finds $35 \%$ of absenteeism related to the dysmenorrhea. Klein and Litt [7] reported a rate of $25 \%$ while Andersch and Milsom [3] found 15.4\% of absenteism. It is indeed a social phenomenon with a considerable socio-economic repercussion since dysmenorrhea is responsible for 600 million hours lost a year in the United States, representing two million dollars and 30 million hours lost in France $[12,13,7,14,15,6]$. The use of clinical score enabled us to obtain $68.7 \%$ from light dysmenorrhea, $27.1 \%$ of moderate dysmenorrhea and $4.2 \%$ of severe dysmenorrhea. Klein and Litt [7] in their study in the United States found 49\% from light dysmenorrhea, 37\% of moderate dysmenorrhea and $14 \%$ of severe dysmenorrhea. A psychological problem of order was found at $41.1 \%$ of the painful menses teenagers during our study. The psychological factors were evoked from time immemorial in so far as the pain will be an element of attraction or attention of the other people on oneself. The cyclic character of the pain becomes a "recall then". In our study, $71.2 \%(n=163)$ had a primary dysmenorrhea and
$23.8 \%(n=51)$ a secondary dysmenorrhea. It is known as that the primary dysmenorrhea is the prerogative of the young teenager before 20 years, and the secondary dysmenorrhea occurs rather after 20 years [10].

\section{Statistical analysis}

\section{Type of dysmenorrhea in function of Age}

We observed that primary dysmenorrhea occurred mainly between the age of 13 years and 16 years. On the other hand, the secondary dysmenorrhea is more frequently observed at more advanced age in particular between 17 years and 19 years [Khi2 $=28.85, p=0.0000001]$. This difference is statistically significant. These results can be explained by the immaturity of the hypothalamo-hypophyso-ovarian axis creating a hormonal imbalance in the case as of primary dysmenorrhea and the exposure to etiologic factors in the case of secondary dysmenorrhea.

\section{Type of Dysmenorrhea in function of Menarche Age}

Primary dysmenorrhea is more frequent when the first menses occurs after the age of 13 years [Khi2 $=27.17, p=$ $0.0000009]$. This difference is statistically significant. The survey of Andersch [3], emphasiezed that dysmenorrhea is frequency higher if the first menses occurs earlier.

\section{Severity of Dysmenorrhea in function of Psychological Factors}

Psychological factors affect the severity of dysmenorrhea. 
Table 4: Division of dysmenorrhea by the thinking about it.

\begin{tabular}{|l|l|l|}
\hline Types & Effective & Percentage (\%) \\
\hline Normal & 130 & 38.7 \\
\hline Will passed & 148 & 44.0 \\
\hline For all the live & 10 & 03.0 \\
\hline disease & 33 & 09.8 \\
\hline Indifferent & 15 & 04.5 \\
\hline Total & 336 & 100.0 \\
\hline
\end{tabular}

This marked influence is noted in the moderate and sever dysmenorrhea [Khi2 $=58.78, p=0.000000]$. This difference is statistically significant. According to Sultan CH [11], psychological factors play a central role. They were mentioned every time: refusal of femininity, desire to draw the attention of the entourage, absenteism. We noticed that dysmenorrhea occurs willingly to unique girls raised up by unique mothers (widowed or divorced) or when the phratry is only made of boys. When scholar performance is low, dysmenorrhea is a pretext to miss class.

\section{Type of Dysmenorrhea in function of socio-economic state of parents}

We noticed that primary dysmenorrhea occurs frequently in high socio-economic category. One can see there a great availability of parents to listen to and take care of the pains of their teenagers. On the second hand, secondary dysmenorrhea is observed with a higher frequency in low socio-economic category. It can be explained by a great risk exposure to various supporting factors. This difference is significant [Khi2 $=7.73, p=0.0054416]$. Klein [7] had found a correlation between the dysmenorrhea and the socio-economic statute. It is more frequent in high socioeconomic category.

\section{Conclusion}

Dysmenorrhea in the teenager is becoming more and more frequent during gynecological consultation in our department. It affects more than one teenager over three during our survey. Psychological factors must be taken into account in the moderate and sever dysmenorrhea. Primary dysmenorrhea is the most frequent and as for the secondary one, it develops on a lesion context.

\section{References}

1. Abel Mh, Baird DT. The effect of $17 \beta$ estradiol and progesterone on prostaglandin production by human endométrium maintained in organ culture. Endocrinology. 1980;106(5):1599-1606.

2. Alvin PE, Litt IF. Current status of the étiology and management of dysmenorrhea in adolescence. Pediatrics. 1982;70(4):516-525.

3. Andersch B, Milson I. An epidemiological study of young women with dysmenorrhea. Am J Obstet Gynaecolo. 1982;144(6):655-660.

4. Akerlund M. Pathophysiology of dysmenorrhea. Acta Obstet Gynecol scand. 1979;87(suppl):27-32.

5. Bersjot P. Socio-economic implications of dysmenorrhea. Acta Obstetric Gynaecology scand. 1979;58(87):67-68.

6. Widholm 0. Dysmenorrhea during adolescence. Acta Obstetrica et Gynecology scand 1979;58(87):61-66.

7. Klein JR, Litt IF. Epidemiology of adolescent dysmenorrhea. Pediatric. 1981;68(5):661-664.

8. Sjöberg No. Dysmenorrhea and uterine neurotransmetters. Acta Obstet Gynecol scand. 1979;58(87):57-59.

9. Ng Tp, Tan Nc, Wansaicheong Gk. A prevalence study of dysmenorrhea in female resident aged 15-54 years in Clementi town, Singapore. Ann Acad Med. 1992;21(3):323-327.

10. Fignon A., Pagneux JM, Perrotin F., Marret H., Akpadza K. et Body G. Dysmenorrhea. Encyclopedy Medico- Chirurgical (Elsevier, Paris), Gynecology, 161-A-10,1795,7p.

11. Sultan Ch. - Teenager dysménorrhea. Clinical, biological and therapeutique results. Revue Fr Gynecol Obstet 1986 ; 815 :253-256.

12. Dawood MY. Dysmenorrhea. Clin obstet gynecol 1990;33(1):168-178.

13. Drapier E., Mikaelian S. Traitement of dysmenorrhea. Revue Fr Gynecol Obstet $1981 ; 76: 67-72$.

14. Polaneszky MM, Slap GB. Menstrual disorder in the teenage: dysmenorrhea and dysfunctional uterine bleeding. Pediatr Rev. 1992;13(3):83-87.

15. Svanberg L, Ulmsten U.The incidence of primary dysmenorrhea in teenagers. Arch gynecol. 1981;230(3):173-177. 